\title{
Resenha: Geoturismo, geodiversidade e geoconservação: abordagens geográficas e geológicas
}

\author{
Revisión: Geoturismo, geodiversidad y geoconservación: \\ enfoques geográficos y geológicos
}

\section{Review: Geotourism, Geodiversity, and Geoconservation: Geographical and Geological Approaches}

\author{
GUERRA, Antonio José Teixeira; JORGE, Maria do Carmo Oliveira (Organizadores). \\ São Paulo: Oficina de Textos, 227p. 2018.ilus. \\ Marcos Antonio Leite Nascimento \\ caxexa@yahoo.com.br \\ Universidade Federal do Rio Grande do Norte, UFRN, Natal, RN
}

O livro Geoturismo, Geodiversidade e Geoconservação: abordagens geográficas e geológicas com suas 227 páginas (sendo 17 páginas de fotos coloridas ao final da publicação), mostra o quão amplo é o tema a que se dedica. O mesmo é ricamente ilustrado (com fotos e mapas coloridos e em preto e branco), de leitura fácil, permitindo ao leitor enveredar por caminhos (ou 'trilhas') do conhecimento relacionados ao trinômio Geodiversidade, Geoconservação e Geoturismo. Contudo acredito que o livro vai além desse trinômio alcançado os 5Gs acrescente-se ao trinômio os termos Patrimônio Geológico/Geopatrimônio e Geoparque. Capítulos específicos sobre a relação do meio abiótico com comunidades, solos, cartografia, fósseis e trilhas, de certa forma pouco publicados no Brasil, mostram a importância e ineditismo da obra, sem falar que em capítulos que tratam de conceitos ou temas já publicados nos últimos anos, muitas novidades são apresentadas, deixando o leitor atualizado sobre os diferentes assuntos. Vale salientar que há apenas dez anos atrás foi lançado o primeiro livro acerca deste trinômio, com o título Geodiversidade, Geoconservação e Geoturismo: trinômio importante para a proteção do patrimônio geológico, de Nascimento, Ruchkys e Mantesso Neto. Portanto, sem dúvida nenhuma, este livro é importantíssimo para todos que querem conhecer ou se aprofundar sobre a vertente abiótica da natureza e seus múltiplos usos.

Escrito por diversos autores, de diferentes áreas, especialmente de geologia, geografia e turismo, o livro é organizado em sete capítulos que versam sobre conceitos de geodiversidade, patrimônio geológico, geoturismo e geoconservação (capítulo 1); comunidades locais e sua importância (capítulo 2); geoparques (capítulo 3); solos (capítulo 4); cartografia da geodiversidade (capítulo 5); fósseis (capítulo 6) e trilhas (capítulo 7).

No primeiro capítulo - Patrimônio Geológico, Geoturismo e Geoconservação: uma abordagem da geodiversidade pela vertente geológica - a geóloga Kátia Leite Mansur mostra a importância e a relação da geologia com as questões ambientais e dedica-se a uma “... 
discussão conceitual sobre geodiversidade, patrimônio geológico, geoconservação e geoturismo pela vertente da geologia ...", apresentando a evolução desses vários conceitos. Em seguida apresenta os diferentes valores e as ameaças sofridas pela geodiversidade e sua relação com os serviços ecossistêmicos, bem como aborda questões sobre avaliações qualitativas e quantitativas, demonstrando algumas metodologias avaliativas. Ainda no capítulo, a autora trata da relação entre patrimônio geológico e geopatrimônio, e discute os desafios para a proteção desse tipo de patrimônio. Em seguida coloca o geoturismo como algo desafiador para a promoção do conhecimento acerca do meio abiótico, discutindo questões de interpretação e o significado do geoturismo urbano. Por fim aborda as questões da geoconservação e apresenta os diferentes passos para elaboração das estratégias de geoconservação, desde o inventário até o monitoramento. Ao final faz uma breve introdução do conceito de geoparque. Este capítulo, um dos mais longos do livro, é de suma importância para aqueles que se iniciam nos estudos e pesquisas sobre a temática abiótica da natureza, ou mesmo para aqueles que querem atualizar seus conhecimentos.

No segundo capítulo - O papel das comunidades locais, sua importância e os novos desafios acerca da sustentabilidade ambiental - a geógrafa Maria do Carmo Oliveira Jorge destaca a importância da geodiversidade nas questões ambientais e a relação direta das comunidades com a conservação do patrimônio natural abiótico. Na sequência a autora aponta a relação existente entre unidades de conservação e geoparques, suas semelhanças e diferenças. Mais adiante são tratados temas e diferentes exemplos de inserção de programas educativos, em especial aqueles ligados à valorização do patrimônio geológico. Para encerrar o capítulo a autora aborda a questão do geoturismo e o desenvolvimento local trazendo exemplos do Brasil e do exterior. O capítulo constitui uma importante contribuição para aqueles que se interessam em trabalhar a relação entre o meio abiótico e comunidades, possibilitando assim entender o envolvimento comunitário com a geodiversidade e o patrimônio geológico.

No capítulo três - Geoparks: educação, conservação e sustentabilidade - as turismólogas Jasmine Cardozo Moreira e Tatiane Ferrari do Vale discutem aspectos conceituais e históricos acerca dessa nova forma de gestão territorial de um patrimônio geológico ímpar, o 'geoparque'. Em seguida as autoras apresentam a importância do trabalho em rede ao abordar a Rede Global de Geoparques e a lista de geoparques mantida por ela. São apresentados os mecanismos de integração ao grupo e estratégias de manejo e gestão de um geoparque. Em seguida aborda-se os diversos benefícios de um geoparque, com destaque para educação/ensino, geoconservação e divulgação, desenvolvimento socioeconômico local, interpretação do patrimônio geológico, reconhecimento internacional e atuação em rede, gestão holística do meio ambiente, fortalecimento do vínculo identitário e consciência ambiental. No caso dos diferentes benefícios, as autoras ilustram o capítulo com imagens de diversos geoparques visitados. Por fim, é apresentada a relação existente entre geoparques e o envolvimento das comunidades, tratando das questões ligadas a sustentabilidade e oportunidades, não apenas as oportunidades específicas para o desenvolvimento do turismo em si, como a promoção da gastronomia local e dos geofoods. Este capítulo é de 
fundamental para todos que trabalham com o tema geoparque, sejam eles estudantes, professores, pesquisadores, gestores e comunidades em geral.

O quarto capítulo - O papel dos solos sob a ótica do geoturismo, da geodiversidade e da geoconservação - do geógrafo Antonio José Teixeira Guerra, visa lembrar a importância das rochas e dos solos como elementos da geodiversidade e seu papel na sustentabilidade dos ecossistemas e na produção sustentável de bens e serviços, bem como das questões pedagógicas ligadas aos solos. Há destaque ao papel do solo na formação de relevo e das diferentes paisagens, bem como em atividades geoturísticas, na ótica das trilhas, dos geossítios e dos pedossítios. Este capítulo é um dos pioneiros no Brasil quanto a caracterização do solo como elemento da geodiversidade e vem em boa hora para aqueles que possuem interesse no assunto.

No quinto capítulo - Cartografia da geodiversidade: teorias e métodos - dos geógrafos Sílvio Carlos Rodrigues e Lilian Carla Moreira Bento, é possível reconhecer a importância da cartografia, com especial destaque para o meio abiótico, e acompanhar a evolução dos conceitos em um breve levantamento histórico. Na sequência são apresentadas diferentes metodologias de mapeamento da geodiversidade, lançando mão de diferentes autores com exemplos de casos no Brasil e no exterior, abordando em sua maioria a questão dos índices da geodiversidade. É um capítulo que estimula e instrumentaliza pesquisadores na utilização de índices de geodiversidade.

O sexto capítulo - Fósseis: importância econômica e social do patrimônio paleontológico - do geólogo Ismar de Souza Carvalho, traz informações acerca deste importante elemento da geodiversidade - o fóssil. É abordado logo de início esse bem patrimonial caracterizando-o como patrimônio paleontológico e com isso são identificados dois elementos importantes para a gestão do território, a identidade social e a relevância econômica. Em seguida esse patrimônio é abordado no contexto geológico (in situ) e ex situ, mostrando a importância do registro fossilífero em diferentes locais. $\mathrm{O}$ autor avança e apresenta a relação do patrimônio paleontológico com duas possibilidades de proteção desse patrimônio, o geopark de acordo com a Unesco, e o paleopark em acordo com a International Paleontological Association (IPA). A diversidade do patrimônio paleontológico, bem como sua relação com o desenvolvimento no Brasil, são apresentadas logo em seguida, sendo demonstrados alguns exemplos como (a) Geopark Araripe; (b) Geoparque Uberaba; (c) Monumento Natural Vale dos Dinossauros; (d) Parque Nacional Serra da Capivara; e (e) Floresta Petrificada de Mata. Por fim, o autor aborda as diretrizes para o desenvolvimento econômico e social com base no patrimônio paleontológico enfatizando a importância da divulgação, mas antes de tudo, da proteção desse importante patrimônio. Este capítulo surge como uma necessidade para tratar de um dos mais importantes elementos da geodiversidade, bem como um dos que mais atraem as pessoas.

Por fim, o sétimo capítulo - Trilhas: caminhos para o geoturismo, a geodiversidade e a geoconservação - das geógrafas Nadja Maria Castilho da Costa e Flávia Lopes Oliveira, possui o objetivo de mostrar a grande importância das trilhas para a interpretação da geodiversidade e uso no geoturismo. De início são apresentados os elos entre os visitantes/ turistas e a natureza, com destaque para o meio abiótico, para depois mostrar a união entre 
biodiversidade e geodiversidade no planejamento, manejo e gestão de trilhas. Neste caso são apresentados alguns exemplos no Brasil e Portugal. Em seguida o tema abordado é a educação ambiental na manutenção da geodiversidade e da prática do geoturismo com algumas proposições de diferentes trilhas. Por fim as autoras colocam suas experiências para os leitores por meio de algumas trilhas e caminhos realizados. As autoras foram muito felizes em tratar de um tema onde muitas vezes se prevê apenas a contemplação da geodiversidade e o patrimônio geológico. Nesta proposta, através das trilhas, pode-se avançar com o entendimento e interpretação dos mesmos.

Parabenizo os autores dos diferentes capítulos e aos organizadores desta obra. Que a mesma alcance o máximo possível de leitores, de diferentes áreas e formações, para a concretização do objetivo de popularização do conhecimento geocientífico. 